\title{
Validation of Glomerular Basement Membrane Thickness Changes with Aging in Minimal Change Disease
}

\author{
Shigeru Sato ${ }^{a}$ Yoshihiro Sasaki $^{a} \quad$ Akiko Adachi $^{a} \quad$ Mohammad Ghazizadeh $^{\mathrm{a}}$ b \\ ${ }^{a}$ Central Institute for Electron Microscopic Researches, Nippon Medical School, Tokyo, and \\ ${ }^{b}$ Department of Molecular Pathology, Institute of Development and Aging Sciences, Graduate School of Medicine, \\ Nippon Medical School, Kawasaki, Japan
}

\section{Key Words}

Glomerular basement membrane thickness changes • Minimal change disease $\cdot$ Aging $\cdot$ Electron microscopy • Histogram plotting

\begin{abstract}
Measurement of the normal range of glomerular basement membrane (GBM) thickness by electron microscopy is required for the diagnosis of thin basement membrane disease or diabetic nephropathy; however, this measurement is influenced by aging. The aim of this study was to introduce a simple histogram plotting method for the validation of the results of the GBM thickness measurements by the accepted arithmetic mean \pm SD method. We examined renal biopsy specimens obtained from 19 patients (10 males and 9 females) with minimal change disease, ranging in age from 3 to 70 years. Renal tissue samples obtained at autopsy from a male baby ( 3 months old) with no renal disease were also examined. For each case, GBM thicknesses at 10-15 evenly distributed points per glomerular loop were directly measured and the arithmetic mean \pm SD was calculated. Subsequently, the arithmetic mean \pm SD for each group of cases classified by age into 4 groups, i.e. babyhood ( 3 months old), childhood (3-11 years old), adulthood (12-57 years old), and
\end{abstract}

old age (60-70 years old), was determined. On the other hand, a histogram of the frequency of GBM points measured against thickness was plotted to determine the distribution pattern and the range of measurements in each age group. The histogram plot showed 4 clearly divided modes for GBM thickness. Comparison of the results obtained by the 2 methods revealed a significant correlation indicating the feasibility of the histogram plotting method as a useful adjunct to validate GBM thickness measurements.

Copyright $\odot 2011$ S. Karger AG, Basel

\section{Introduction}

Glomerular basement membrane (GBM) thickness is not exactly determinable visually by electron microscopy. Thus, measurement of the GBM thickness is required for the diagnosis of thin basement membrane nephropathy [1-14], prediabetes, and diabetic nephropathy [15-17]. One undesirable factor that influences this measurement is age-related changes. Several methods have been introduced for the measurement of GBM thickness; however, there are no standard criteria for defining the lower limit of normal GBM thickness below which the GBM can be considered thin. In addition, there is considerable vari-

\section{KARGER}

Fax +41613061234 E-Mail karger@karger.ch www.karger.com
(C) 2011 S. Karger AG, Basel

$1015-2008 / 10 / 0776-0315 \$ 26.00 / 0$

Accessible online at:

www.karger.com/pat
M. Ghazizadeh, MD, PhD

Director, Central Institute for Electron Microscopic Researches

Nippon Medical School

1-1-5 Sendagi, Bunkyo-ku, 113-8602 Tokyo (Japan)

E-Mail ciem@nms.ac.jp 
Table 1. Clinical findings and GBM thickness of the patients by the arithmetic mean method (mean $\pm \mathrm{SD}$ ) and histogram peak

\begin{tabular}{|c|c|c|c|c|c|c|}
\hline \multirow{2}{*}{$\begin{array}{l}\text { Case } \\
\text { No. }\end{array}$} & \multirow{2}{*}{$\begin{array}{l}\text { Age } \\
\text { years }\end{array}$} & \multirow[t]{2}{*}{ Sex } & \multirow{2}{*}{$\begin{array}{l}\text { Micro- } \\
\text { hema- } \\
\text { turia }\end{array}$} & \multirow{2}{*}{$\begin{array}{l}\text { Pro- } \\
\text { teinuria }\end{array}$} & \multicolumn{2}{|l|}{ Method $^{1}$} \\
\hline & & & & & $\begin{array}{l}\text { arithmetic } \\
\text { mean, nm }\end{array}$ & $\begin{array}{l}\text { histogram } \\
\text { peak, nm }\end{array}$ \\
\hline 1 & 0.25 & $\mathrm{M}$ & - & - & $115 \pm 36$ & 125 \\
\hline 2 & 3 & M & $1+$ & $2+$ & $250 \pm 53$ & 250 \\
\hline 3 & 4 & $\mathrm{M}$ & - & $2+$ & $268 \pm 75$ & 225 \\
\hline 4 & 6 & $\mathrm{M}$ & $2+$ & $1+$ & $298 \pm 116$ & 250 \\
\hline 5 & 6 & $\mathrm{~F}$ & $1+$ & $1+$ & $280 \pm 71$ & 225 \\
\hline 6 & 9 & M & $1+$ & $2+$ & $273 \pm 64$ & 250 \\
\hline 7 & 9 & $\mathrm{~F}$ & - & $2+$ & $281 \pm 74$ & 250 \\
\hline 8 & 11 & $\mathrm{M}$ & $1+$ & $2+$ & $271 \pm 78$ & 250 \\
\hline 9 & 12 & $\mathrm{M}$ & $1+$ & $3+$ & $353 \pm 76$ & 325 \\
\hline 10 & 12 & $\mathrm{~F}$ & $1+$ & $2+$ & $370 \pm 50$ & 350 \\
\hline 11 & 14 & $\mathrm{~F}$ & $2+$ & $2+$ & $371 \pm 62$ & 325 \\
\hline 12 & 20 & $\mathrm{M}$ & $3+$ & $2+$ & $458 \pm 110$ & 375 \\
\hline 13 & 22 & $\mathrm{~F}$ & - & $3+$ & $373 \pm 64$ & 350 \\
\hline 14 & 38 & $\mathrm{M}$ & - & $4+$ & $399 \pm 75$ & 375 \\
\hline 15 & 42 & $\mathrm{~F}$ & $2+$ & $2+$ & $440 \pm 108$ & 375 \\
\hline 16 & 57 & $\mathrm{~F}$ & $1+$ & $2+$ & $398 \pm 104$ & 350 \\
\hline 17 & 60 & $\mathrm{M}$ & $2+$ & $2+$ & $314 \pm 73$ & 300 \\
\hline 18 & 65 & $\mathrm{M}$ & $1+$ & $3+$ & $274 \pm 48$ & 300 \\
\hline 19 & 69 & $\mathrm{~F}$ & $1+$ & $2+$ & $359 \pm 95$ & 300 \\
\hline 20 & 70 & $\mathrm{~F}$ & $2+$ & $4+$ & $239 \pm 56$ & 250 \\
\hline
\end{tabular}

${ }^{1}$ Pearson's correlation coefficient 0.94973 ; 95\% CI 0.87491184 and $0.9802686 ; \mathrm{p}<0.05$.

ability between the values established at this lower limit at different centers and with different methodologies.

The most frequently used method for ultrastructural morphometric measurements of GBM thickness is the direct measurement method $[6,18]$. The individual GBM thickness measurements from the glomeruli range between maximum and minimum values or are pooled to produce a mean GBM thickness and standard deviation (SD). However, extreme values in SD have been affected by the mean; thus, further adjunct methods are needed to validate such results.

The aim of this study was to introduce a simplified histogram plotting method for the validation of the results of GBM thickness measurements by the accepted arithmetic mean $\pm \mathrm{SD}$ method. We used this method in minimal change disease (MCD) without diabetes in different age groups and compared the results with those obtained by the arithmetic mean \pm SD method. Our findings suggest that the histogram plotting method is efficiently comparable and thus may be used to validate GBM thickness measurements.

\section{Subjects and Methods}

\section{Renal Tissues}

We studied renal biopsy tissue sections from 19 patients (10 male and 9 female) with MCD ranging in age from 3 to 70 years. In addition, a renal tissue specimen from the autopsy of a threemonth-old male infant with lymphoma was also examined. The biopsies had been performed using a standard technique under local anesthesia. In each case, the diagnosis had been made based on light microscopic examination of hematoxylin and eosin-stained sections and immunofluorescence and transmission electron microscopy results. All 19 patients in this study presented unremarkable histological findings on light microscopy and negative immunofluorescence. The epoxy resin-embedded renal biopsy blocks were obtained from the pathology files at the Nippon Medical School Hospital. Clinicopathological factors including the patient's age, sex, microhematuria, and proteinuria were recorded (table 1).

\section{Transmission Electron Microscopy}

Renal biopsy specimens had been fixed in $2.5 \%$ glutaraldehyde and $1 \%$ osmium tetroxide, dehydrated in graded series of ethanol, and embedded in Epok 812. Ultrathin sections were cut, stained with uranyl acetate and lead citrate, and examined under a transmission electron microscope (H-7650; Hitachi, Tokyo, Japan).

\section{Measurement of GBM Thickness}

Two methods were used for estimating the thickness of GBMs in each patient and on the same ultrathin sections. In the first method, referred to as the arithmetic mean \pm SD, measurements were taken at $10-15$ evenly distributed points per loop (fig. 1). This method was basically identical to that described by Marquez et al. [6], except that the number of evaluation points was 2-3 fold increased. Two glomeruli from each biopsy specimen were examined. A total of 15-18 electron micrographs of nonoverlapping fields were taken from each glomeruli at a constant magnification of $\times 5,000$. The printed micrographs had a final magnification of $\times 10,000$. An average of 180 points was measured per case, after which the arithmetic mean \pm SD for GBM thickness was determined for each patient. Finally, the arithmetic mean \pm SD for each group of cases classified by age into babyhood ( 3 months old), childhood (3-11 years old), adulthood (12-57 years old), and old age (60-70 years old) was calculated and recorded.

In the second method termed 'histogram plotting', a line histogram was plotted illustrating the frequency of GBM points measured against thickness to determine the distribution pattern for each age group, and the ranges of measurements were recorded.

\section{Statistics}

Correlation between the results obtained by the arithmetic mean and histogram plotting methods was assessed using the Pearson correlation coefficient test. $p<0.05$ was considered statistically significant.

\section{Results}

We measured GBM thickness in renal biopsies with MCD in order to determine changes introduced by age. Since it is difficult to distinguish between the lamina rara 
Fig. 1. Electron micrograph of the glomerular loop from a case of MCD shows effacement of foot processes (FP) of the visceral epithelial cells. Circles indicate points at which GBM thickness was directly measured. GBM thickness was measured at $10-15$ evenly distributed points per loop (dots) (magnification $\times 10,000$ ). The oblique angle in the loop was excluded from the measurement.

Fig. 2. The histogram plot of the frequency of GBM points measured against thickness shows a near normal distribution pattern and 4 distinct groups of babyhood (dot marked/green in the online version), childhood (dark grey/red), adulthood (black/deep blue), and old age (light grey/ yellow) graphs. $\mathrm{M}=$ Male; $\mathrm{F}=$ female.
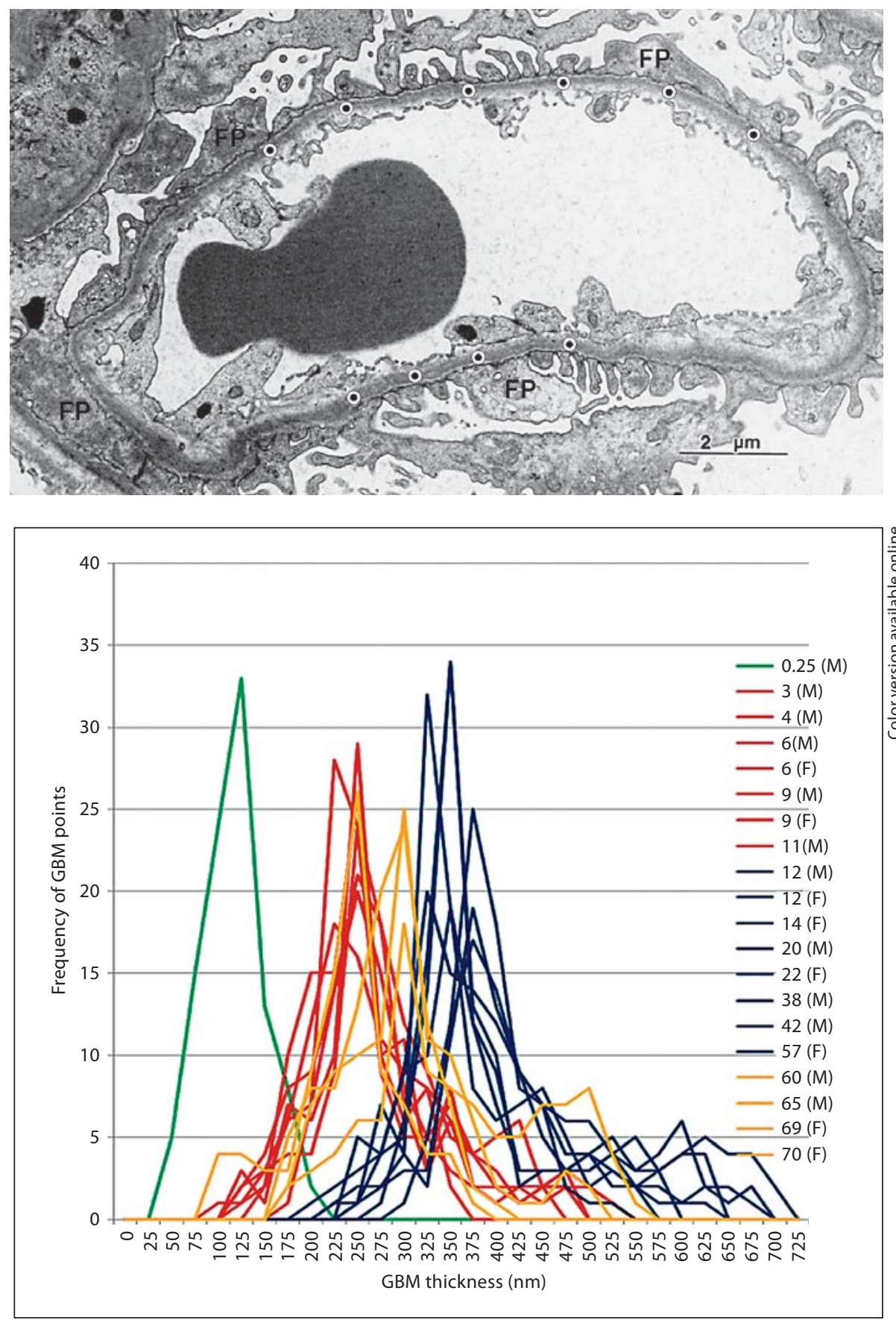

interna and subendothelial edema at a low magnification, the GBM thickness width was measured in electron micrographs at a high magnification $(\times 10,000$; fig. 1$)$.

Using the arithmetic mean \pm SD method, the mean GBM thickness in babyhood (1 case, 3 months old) was 115 $\pm 36 \mathrm{~nm}$ (table 1). In the childhood group consisting of 7 patients ranging in age from 3 to 11 years, the mean thick- ness was $243 \pm 12 \mathrm{~nm}$. In the adulthood group comprising 8 patients with an age range of $12-57$ years, the mean thickness was $353 \pm 20 \mathrm{~nm}(358 \pm 26 \mathrm{~nm}$ in males and $350 \pm 17 \mathrm{~nm}$ in females). In the old-age group with $4 \mathrm{pa}-$ tients ranging in age from 60 to 70 years, the mean was 287 $\pm 25 \mathrm{~nm}$. GBM thickness did not tend to increase in adults and it was not distinctive between male and female sexes. 
Using the histogram plotting method, the frequency histograms showed a near normal distribution pattern (fig. 2). Based on the histogram mode, the peak GBM thickness was $125 \mathrm{~nm}$ in babyhood (dot-marked graph/ green in the online version) and ranged from 225 to 275 $\mathrm{nm}$ in childhood (dark grey graph/red), from 325 to 375 $\mathrm{nm}$ in adulthood (black graph/blue), and from 250 to 300 $\mathrm{nm}$ in old age (light grey graph/yellow). In the adulthood group, the histogram peak showed a significantly higher GBM thickness than in the babyhood, childhood, or oldage groups. A GBM thickness of more than $600 \mathrm{~nm}$ was only observed in the adulthood group.

Statistical analysis of the correlation between the GBM thicknesses measurements obtained by the arithmetic mean \pm SD and histogram plotting methods revealed a significant correlation (Pearson's correlation coefficient 0.94973 ; 95\% CI 0.87491184 and 0.9802686 ; $\mathrm{p}<0.05$ ) (table 1).

\section{Discussion}

Measurement of GBM thickness is usually performed using either methods of arithmetic or a harmonic mean with a little difference in the results [18]. In the present study, we used the arithmetic mean \pm SD method to measure normal GBM thicknesses. In parallel, we plotted a histogram of the frequency of GBM points measured against thickness and determined the range of GBM thickness measurements for each age group.

The histogram mode of GBM thickness was clearly divided into 4 groups, i.e. babyhood $(125 \mathrm{~nm})$, childhood (225-275 nm), adulthood (325-375 nm), and old age $(250-300 \mathrm{~nm})$. Our results indicated that GBM thickness does not constantly increase with increasing age. Instead, it rapidly increases at ages 1-2 and 11-12 years with no considerable change in thickness at ages 3-11 and 12-57 years. After the age of 60 years, the GBM thickness begins to decrease. In addition, GBM thickness does not differ significantly between males and females at age 3-70 years by either the arithmetic mean $\pm \mathrm{SD}$ method or the histogram method.

The histogram plot of GBM thicknesses showed a near normal distribution pattern for life. In our study, the arithmetic mean \pm SD of 4-year-old $(268 \pm 75)$ and 6-year-old (298 \pm 116$)$ patients was different, but both values of the histogram mode were the same $(250 \mathrm{~nm})$. The mean GBM thickness of 20-year-olds (458 \pm 110 $\mathrm{nm})$ and 38-year-olds (399 $\pm 75 \mathrm{~nm})$ was different too, but both values of histogram mode were the same (375 $\mathrm{nm})$. These results indicated that GBM thickness can be well-defined by histogram mode values in addition to the mean $\pm \mathrm{SD}$. In our study, the mean range of GBM thickness was $269-273 \mathrm{~nm}$ in childhood, $371-458 \mathrm{~nm}$ in adulthood and 239-359 $\mathrm{nm}$ in old age. Especially in adults, the assessment of variation in the mean \pm SD is difficult because of the high SD values. However, this problem is avoided when using histogram mode values. The histogram mode values ranged from 225 to $275 \mathrm{~nm}$ in childhood, from 325 to $375 \mathrm{~nm}$ in adulthood, and from 250$300 \mathrm{~nm}$ in old age. Babyhood, childhood, and adulthood groups were clearly divided by the histogram mode values. The modes in histograms were not affected by extreme values of the mean and SD. Thus, histogram plotting is useful to validate GBM thickness measurements.

GBM thickness did not increase continuously with age. It rapidly increased at age 1-2 years at first $[18,19]$ and then rapidly increased at age 11-12 years. After the age of 60 years, GBM thickness decreased, being the same at the age of 70 years as in childhood. In addition, previous studies showed that GBM thickness does not cause an increase in the degree of proteinuria [20]. Our study results are in agreement with this report. GBM thickness did not correlate with the degree of hematuria or proteinuria.

Comparison of the GBM thicknesses obtained by the arithmetic mean \pm SD method and the histogram plotting method revealed a significant correlation suggesting the feasibility of the histogram plotting method as a simple and reliable approach to validate GBM thickness measurements.

It should be noted that we have not attempted to define a cutoff or range for normal GBM thickness changes with aging but have simply compared 2 measurement methods in order to provide a simple adjunct method for the validation of the GBM thickness measurement. Previous studies on transplant donor biopsies reported a normal GBM thickness range of 236-416 $\mathrm{nm}$ for women and 289-457 $\mathrm{nm}$ for men using the orthogonal intercept method (mean $\pm 2 \mathrm{SD}$ ), which corresponds to lower limits of $156 \mathrm{~nm}$ and $209 \mathrm{~nm}$ respectively by the direct method [21].

In conclusion, we have introduced a histogram plotting method which is simple and potentially useful for the validation of GBM thickness measurements in the diagnosis of thin basement membrane disease by electron microscopy. Further application of this method in GBM thickness changes with aging will add support to its feasibility. 


\section{References}

-1 Coleman M, Haynes WD, Dimopoulos P, Barratt LJ, Jarvis LR: Glomerular basement membrane abnormalities associated with apparently idiopathic hematuria: ultrastructural morphometric analysis. Hum Pathol 1986;17:1022-1030.

$\checkmark 2$ Abe S, Amagasaki Y, Siyori S, Konishi K, Kato E, Sakaguchi H: Thin basement membrane syndrome in adults. J Clin Pathol 1987; 40:318-322.

3 Tiebosch AT, Frederik PM, van Breda Vriesman PJ, Mooy JM, van Rie H, van de Wiel TW, Wolters J, Zeppenfeldt E: Thin-basement-membrane nephropathy in adults with persistent hematuria. N Engl J Med 1989; 320:14-18.

$\checkmark 4$ Dische EF, Anderson VE, Keane SJ, Taube D, Bewick M, Parsons V: Incidence of thin membrane nephropathy: morphometric investigation of a population sample. J Clin Pathol 1990;43:457-460.

5 Mclay AL, Jackson R, Meyboom F, Jones JM: Glomerular basement membrane thinning in adults: clinicopathological correlations of a new diagnostic approach. Nephrol Dial Transplant 1992;7:191-199.

-6 Marquez B, Zouvani I, Karagrigoriou A, Anastasiades E, Pierides A, Kyriacou K: A simplified method for measuring the thickness of glomerular basement membranes. Ultrastruct Pathol 2003;27:409-416.

7 Savige J, Rana K, Tonna S, Buzza M, Dagher H, Wang YY: Thin basement membrane nephropathy. Kidney Int 2003;64:1169-1178.
8 Van Passen P, van Breda Vriesman PJC, van Rie H, Cohen Terwaert JW: Signs and symptoms of thin basement membrane nephropathy: a prospective regional study on primary glomerular disease. Kidney Int 2004;66: 909-913.

-9 Rayat CS, Joshi K, Sakhuja V, Datta U: Glomerular basement membrane thickness in normal adults and its application to the diagnosis of thin basement membrane disease: an Indian study. Indian J Pathol Microbiol 2005;48:453-458.

10 Akashi T, Minami J, Ishige Y, Eishi Y, Takizawa T, Koike M, Yanagishita M: Basement membrane matrix modifies cytokine interactions between lung cancer cells and fibroblasts. Pathobiology 2005;72:250-259.

11 Frasca GM, Onetti-Muda A, Mari F, Longo I, Scala E, Pescucci C, Roccatello D, Alpa M, Coppo R, Li Volti G, Feriozzi S, Bergesio F, Schena FP, Renieri A: Thin glomerular basement membrane disease: clinical significance of a morphological diagnosis - a collaborative study of the Italian Renal Immunopathology Group. Nephrol Dial Transplant 2005;20:545-551.

12 Carasi C, Van't Hoff WG, Rees L, Risdon RA Trompeter RS, Dillon MJ: Childhood thin GBM disease-review of 22 children with family studies and long-term follow-up. Pediatr Nephrol 2005;20:1098-1105.

13 Ivanyi B, Pap R, Ondrik Z: Thin basement nephropathy: diffuse and segmental types. Arch Pathol Lab Med 2006;130:1573-1537.
14 Hass M: Thin glomerular basement membrane nephropathy incidence in 3,471 consecutive renal biopsies examined by electron microscopy. Arch Pathol Lab Med 2006;130: 699-706.

15 Mauiyyedi S, Selig MK, Marion AP, Colvin $\mathrm{RB}$ : Chapter 12: renal glomerular disease; in Dickersin GR (ed): Diagnostic Electron Microscopy: A Text/Atlas. New York, Springer, 1999, pp 782-911.

16 Mac-Moune LF, Szeto CC, Choi PC, Ho KK, Tang NL, Chow KM, Li PKT, To KF: Isolate diffuse thickening of glomerular capillary basement membrane: a renal lesion in prediabetes? Mod Pathol 2004;17:1506-1512.

17 Wagrowska-Danilewicz M, Danilewicz M: Current position of electron microscopy in diagnosis of glomerular disease. Pol J Pathol 2007;58:87-92.

18 Ramage IJ, Howatson AG, McColl JH, Maxwell H, Murphy AV, Beattie TJ: Glomerular basement membrane thickness in children: a stereologic assessment. Kidney Int 2002;62: 895-900.

19 Vogler C, McAdams AJ, Homan SM: Glomerular basement membrane and lamina densa in infants and children: an ultrastructural evaluation. Pediatr Pathol 1987;7:527534.

20 Steffes MW, Barbosa J, Basgen JM, Sutherland DER, Najarian JS, Mauer SM: Quantitative glomerular morphology of the normal human kidney. Lab Invest 1983;49:82-86.

21 Danilewicz M, Wagrowska-Danilewicz M: Glomerular basement membrane thickness in minimal change disease. Pol J Pathol 1998; 49:23-26. 